\title{
Experimental research on compressive properties of concrete with different plastics content
}

\author{
XUAN Wei-hong ${ }^{1, a}$, WU Yun-hao ${ }^{2, b}$ and CHEN Yu-zhi ${ }^{1, c}$ \\ 1 Jinling Institute of Technology, Nanjing 211169, China \\ ${ }^{2}$ Nanjing Qiqiao Construction and Installation Engineering Co., Ltd, Nanjing 21169, China \\ axwh@jit.edu.cn, b113148006@qq.com, cyuzhicihen@jit.edu.cn
}

Keywords: Plastic particles, Concrete, Mechanical properties, Experimental.

Abstract. Compression tests of five groups of concrete specimens with different plastic particles ( $0 \%$, $5 \%, 10 \%, 30 \%$ and $45 \%$ aggregate volume ratio) are carried out. The results show that, the incorporation of plastic particles has significant influence on the mechanical properties of concrete. With the increase of dosage of plastic particles, the compressive strength and elastic modulus of concrete reduce gradually, but the strain corresponding to the maximum intensity shows a rising trend. In addition, the linear sections in concrete stress-strain curve disappears after adding plastic particles.

\section{Introduction}

Plastic products are closely related with people's production and living. According to statistics, the total output of plastic products in the country in 2016 reached 77.17 million tons. So large-scale production and use of plastic products will inevitably produce a large number of waste plastics. Waste plastic is not easy to decompose and decay due to its macromolecule structure, and can be floating in the wind or water with light weight. Environmental pollution caused by waste plastics is becoming more and more serious.

Recycling of waste plastics as a means of conserving energy and protecting the environment is becoming more and more important, and relevant recycling methods have been developed. Broken waste plastic into particles or powder and then mixed with other materials is one of the effective ways ${ }^{[1]}$. Recycled plastic concrete (RPC) is made by using different sizes of plastic particles or debris instead of part of the aggregate.

At present, the recycled plastics used in concrete is still in the laboratory research stage, and the research of recycled plastic concrete is rare. Yun-Wang Choi ${ }^{[2]}$ studied the physical and mechanical properties of lightweight concrete under different water-cement ratio and different plastic content, which is made by grinding the discarded PET bottle into granules and making a lightweight aggregate and then replacing part of the fine aggregate into the concrete. Mariaenrica Frigione ${ }^{[3]}$ did a similar study and studied the stress-strain curves of recycled plastic concrete. Batayneh $\mathrm{M}^{[4]}$, Marzouk ${ }^{[5]}$, Albano $^{[6]}$, Huang Haibin ${ }^{[7]}$, who also carried out a corresponding study of plastic concrete. From the present research results, with the increase of plastic content, the density, elastic modulus and compressive strength of concrete gradually decrease, the ductility of concrete is improved, the performance of recycled plastic concrete has a greater relationship with the shape and size of plastic.

In this paper, the compressive strength of recycled plastic concrete under different plastic particles was studied. The influence of plastic particle content on RPC constitutive relationship was discussed, which provided the experimental basis for RPC engineering application.

\section{Experiment program}

Experiment material. Ordinary Portland cement 42.5, and clean medium sand was used in this test, the maximum diameter of coarse aggregate is $10 \mathrm{~mm}$; The particle size of the plastic particles is 2.36 $\mathrm{mm}$ and the density is about $1 \mathrm{~g} / \mathrm{cm}^{3}$. The particle size of the plastic particles is between the coarse aggregate and the fine aggregate, which are partially replaced by plastic particles. The plastic particles used in this paper are shown in Figure 1, and detailed data of mix is presented in Table 1. 


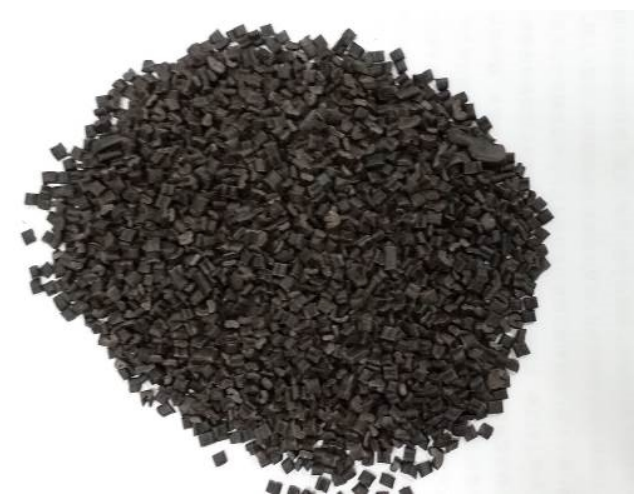

Fig.1 The plastic particles used in this paper

Table 1 Mix proportion of recycled plastic concrete $(\mathrm{kg} / \mathrm{m} 3)$

\begin{tabular}{cccccc}
\hline Specimen name & water & cement & sand & coarse aggregate & plastic particles \\
\hline RPC-0 & 225.5 & 433.6 & 719.8 & 1071.0 & 0 \\
RPC-5 & 225.5 & 433.6 & 683.8 & 1017.5 & 60 \\
RPC-10 & 225.5 & 433.6 & 647.8 & 963.9 & 120 \\
RPC-30 & 225.5 & 433.6 & 503.9 & 749.7 & 360 \\
RPC-45 & 225.5 & 433.6 & 395.9 & 589.1 & 540 \\
\hline
\end{tabular}

Sample preparation. The PVC pipe with an inner diameter of $70 \mathrm{~mm}$ was used and cut to $200 \mathrm{~mm}$ long used to pour concrete. Both ends of the specimen were cut together with PVC pipe after hardened, and the length of specimen is $150 \mathrm{~mm}$ after cutting. The specimen is shown in Figure 2.
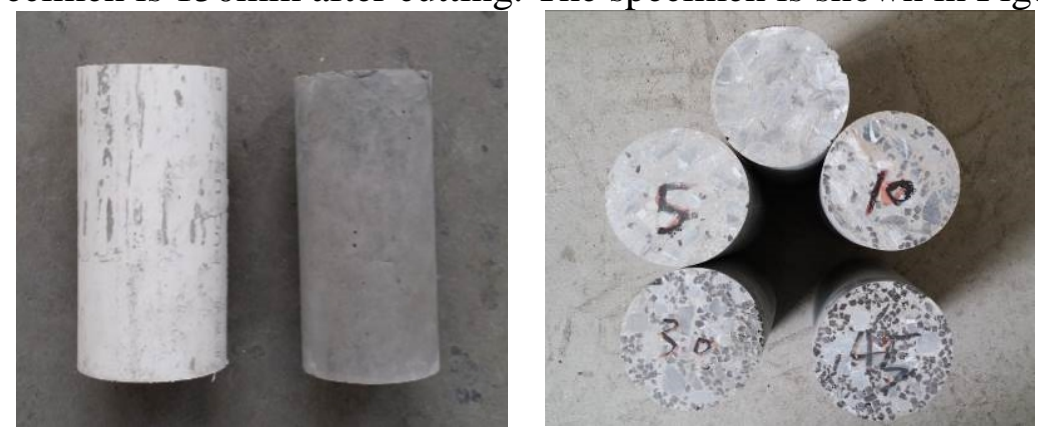

Fig.2 The specimen

Three specimen for each type were adopted and weight, and density is calculated and shown in Table 2. It can be seen from Table 2 that with the increase of the content of plastic particles, the density of plastic concrete gradually decreased. When the volume ratio of plastic content is $45 \%$, the density decreased by $20 \%$.

Table 2 The density of different plastic content of concrete

\begin{tabular}{llllll}
\hline Plastic dosage & $0 \%$ & $5 \%$ & $10 \%$ & $30 \%$ & $45 \%$ \\
\hline density $\left(\mathrm{g} / \mathrm{cm}^{3}\right)$ & 2.44 & 2.40 & 2.29 & 2.13 & 1.96
\end{tabular}

Loading method. In this paper, the MTS hydraulic servo testing machine is used to load. Three extensometers were installed along the circumference of the cylindrical specimen by $120^{\circ}$, axial compression loading is controlled by specimen strain deformation and strain rate is $10-5 / \mathrm{s}$. The test loading device is shown in Figure 3. 


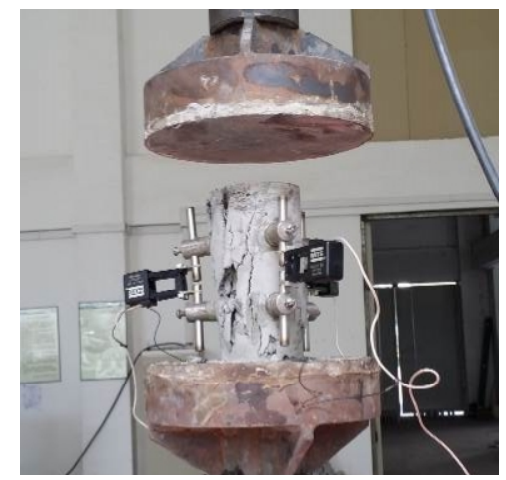

Fig.3 The test loading device

\section{Analysis of test results}

Stress-strain curve. The axial compression test was carried out for ordinary concrete and four different plastic content of concrete, and the stress-strain curve shown in Figure 4 was obtained. Mechanical properties such as strength, elastic modulus are shown in Table 3. It can be seen from Figure 4, the stress-strain curve of ordinary concrete can be clearly divided into linear segments and nonlinear segments, but with the increase of plastic particles the linear section in the stress-strain curve gradually disappears after the plastic particles are incorporated. Concrete is transformed from elastoplastic to plastic after the incorporation of plastic particles.

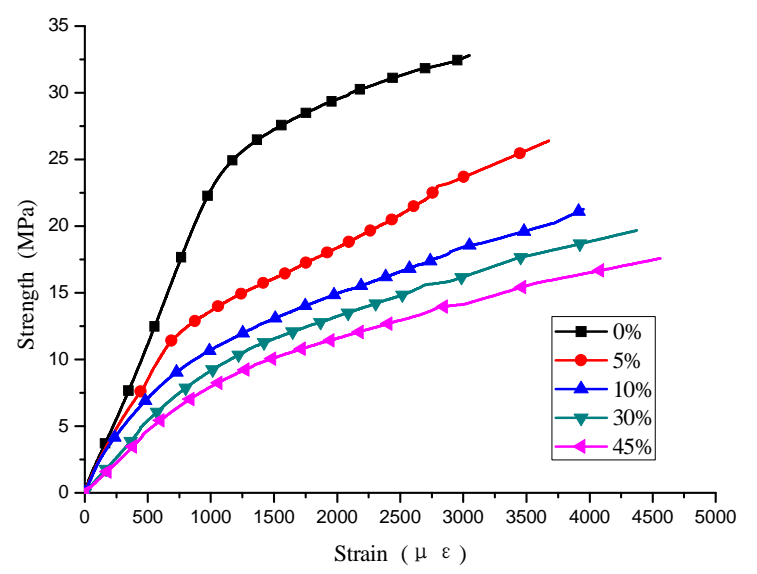

Fig.4 Compression stress-stain curves of RPC with different recycled plastic contents

Table 3 Compression test results of different plastic content concrete

\begin{tabular}{cccc}
\hline Plastic dosage & $\begin{array}{c}\text { Compressive strength } \\
(\mathrm{MPa})\end{array}$ & $\begin{array}{c}\text { Elastic Modulus } \\
(\mathrm{GPa})\end{array}$ & $\begin{array}{c}\text { Deformation of peak intensity } \\
(\mu \varepsilon)\end{array}$ \\
\hline $0 \%$ & 32.8 & 22.9 & 3049 \\
$5 \%$ & 26.3 & 16.3 & 3679 \\
$10 \%$ & 21.3 & 13.8 & 3954 \\
$30 \%$ & 19.7 & 8.0 & 4374 \\
$45 \%$ & 17.6 & 6.7 & 4560
\end{tabular}

Strength. As shown in Figure 5, with the increase of the content of plastic particles, the axial compressive strength of concrete decreases. The axial compressive strength of specimens with 5\%, $10 \%, 30 \%$ and $45 \%$ of plastic particles decreased by $20 \%, 35 \%, 40 \%$ and $47.7 \%$, respectively. Even if the content of plastic particles is low, the axial compressive strength of concrete decreases obviously. 


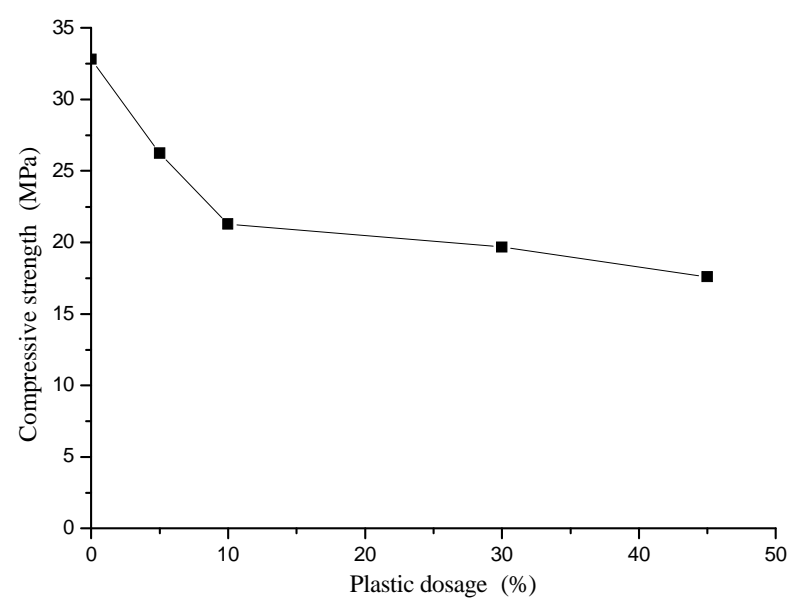

Fig.5 Effect of plastic content on strength

Concrete is a composite of cement paste and aggregate particles, which strength is determined by the aggregate, the mortar, and the bond strength between the aggregate and mortar. The interface transition zone between aggregate and mortar is a weak area in concrete. In particular, the surface of the recycled plastic particles used in this experiment is non-hydrophilic, resulting in a lower adhesive strength between the plastic particles and the cement matrix. The strength of plastic is much smaller than the aggregate and cement also led to the reduction of concrete strength. The higher the plastic content the more interfacial zone between the plastic particles and the cement matrix, so the concrete strength also dropped more.

Deformation. As can be seen from Figure 6, due to the lower plastic modulus of elasticity, the overall elastic modulus of concrete showed a downward trend. The modulus of RPC-45 is about $70 \%$ lower than the RPC-0.

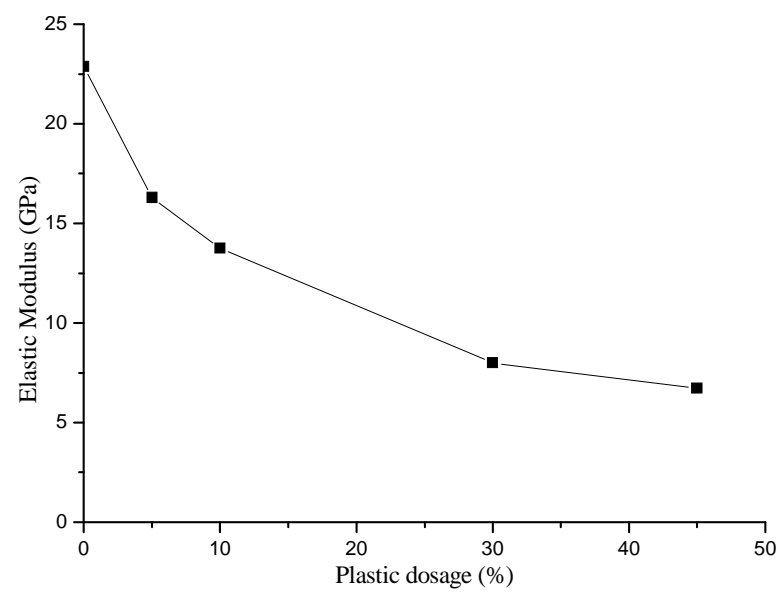

Fig.6 Effect of plastic content on elastic modulus

Ultimate strain is an important indicator of the deformation capacity of concrete. It can be seen from Figure 7 that the ultimate strain of concrete increases with the increase of plastic content. The ultimate strain of RPC-10 increased by $30 \%$ compared with that of RPC-0, and the RPC-45 increased by $50 \%$. The incorporation of plastic particles in ordinary concrete can significantly improve the deformation capacity of concrete. 


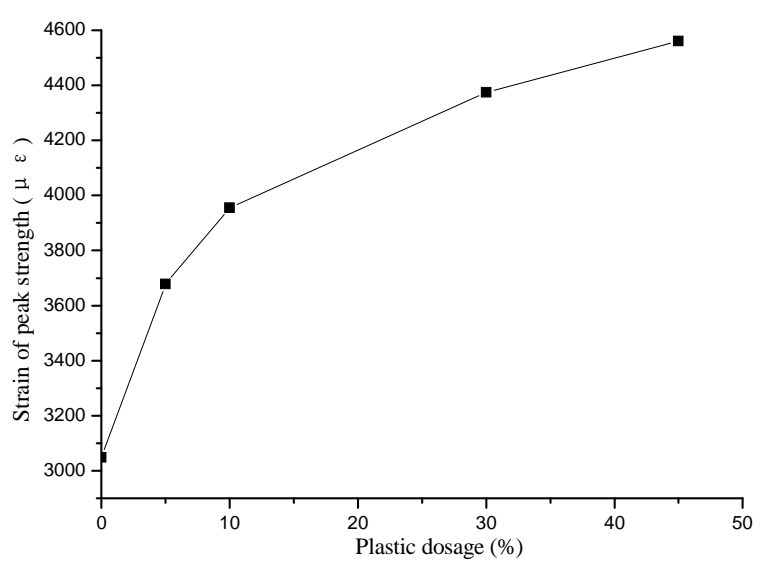

Fig.7 Effect of plastic content on strain of peak strength

\section{Conclusions}

Addition of plastic particles significantly changes the mechanical properties of concrete, mainly in the following two aspects:

Addition of plastic particles reduces the compressive strength of concrete, the greater the dosage, the greater the reduction of strength;

The addition of plastic particles changed the deformation characteristics of concrete. With the increase of the content of plastic particles, the elastic modulus decreased gradually, the strain corresponding to peak strength increased, and the concrete changed from elastoplastic to plastic.

\section{Acknowledgements}

This work was financially supported by the science and technology project of ministry of housing and urban-rural development (2013-K4-36).

\section{References}

[1] HUANG Hai-bin, LIU Feng, LI Li-juan. Reutilization of plastic and application of recycled plastic in construction materials[J]. Engineering Plastics Application, 2009, 37(7): 56-59. (In Chinese)

[2] Choi Y, Moon D, Chung J, et al. Effects of waste PET bottles aggregate on the properties of concrete[J]. Cement and Concrete Research, 2005, 35(4): 776-781.

[3] Frigione M. Recycling of PET bottles as fine aggregate in concrete[J]. Waste Management, 2010, 30(6): 1101-1106.

[4] Batayneh M, Marie I, Asi I. Use of selected waste materials in concrete mixes[J]. Waste Management, 2007, 27(12): 1870-1876.

[5] Marzouk O Y, Dheilly R M, Queneudec M. Valorization of post-consumer waste plastic in cementitious concrete composites[J]. Waste Management, 2007, 27(2): 310-318.

[6] Albano C, Camacho N, Hernandez M, et al. Influence of content and particle size of waste pet bottles on concrete behavior at different w/c ratios[J]. Waste Management, 2009, 29(10): 2707-2716.

[7] LIU Feng, HUANG Hai-bin, XIA Xiao-zhou, et al. Mechanical Test on Modified Concrete with Recycled Plastic Particles and Its Numerical Simulation [J]. Journal of Building Material, 2011, 14(2), 173-179. (In Chinese) 